\title{
Adaptable test rig for two-stage axial turbine
}

\author{
Martin Němec ${ }^{1 *}$, and Tomáš Jelínek ${ }^{1}$ \\ ${ }^{1}$ VZLU - Czech Aerospace Research Centre, Beranových 130, 199 05, Prague - Letňany, Czech \\ Republic
}

\begin{abstract}
This contribution describes a new test rig for a two-stage axial turbine built in the VZLÚ. The test rig has replaced an original facility used for a full stage aerodynamics investigation. The motivation for the design of the new test facility was the limitations of the original one. The design is briefly discussed, and then the first measurement results are presented. The first operation was performed with a turbine stage already measured in the original facility. This allows the comparison of the most important quantities.
\end{abstract}

\section{Introduction}

The investigation of flow fields in turbomachines is one of the basic fields of research that VZLÚ has been engaged in for a long time. It is partially due to long-term cooperation with the world's leading producers of turbomachines. Since 2010, a measuring device has been put into operation at the VZLÚ, which enabled flow research on a single-stage axial turbine stage: measurement of integral characteristics using a water dynamometer and measurement of flow fields by traversing behind the stator and rotor blades [1], [2]. Thanks to this device, it was possible to bring new knowledge to the research of flow in the turbine stages and a lot of data to refine the producer's design models [3], [4].

During its operation, the device was gradually improved. Its arrangement was expanded to a one-and-half stage by adding a subsequent stator behind the stage. The shape and positions of both shaft and rotor shroud seals were also improved over the past decade according to the requirements of individually designed projects [5], [6].

At present, in cooperation with industrial partners, there is an increasing demand for research into the mutual interaction of purge flows emerging from seals with the main flow in the turbine and mutual interaction in applications of multistage arrangements. Research of design-overloaded stages with non-axial inlet is also a topic of today.

The above-mentioned new demand in the field of research, together with the broad experience gained by operating the existing experimental turbine, has necessitated the creation of a new test rig concept that would allow research on a two-stage axial test stage.

\footnotetext{
* Corresponding author: nemec@,vzlu.cz
} 


\section{Basic concept of the new test rig}

The basic concept of the newly created device is based on the original device (section shown in Fig. 1), which was part of a closed-loop wind tunnel (depicted in Fig. 2) driven by a turbocompressor with a power of $1.3 \mathrm{MW}$ and providing the mass flow of $7 \mathrm{~kg} / \mathrm{s}$. To minimize costs, it was decided to use the existing Froude-Hoffman F249-RACE-GT water dynamometer for loading the turbine stage with a maximum loading power of $700 \mathrm{~kW}$, and a maximum speed of $15,000 \mathrm{rpm}$.

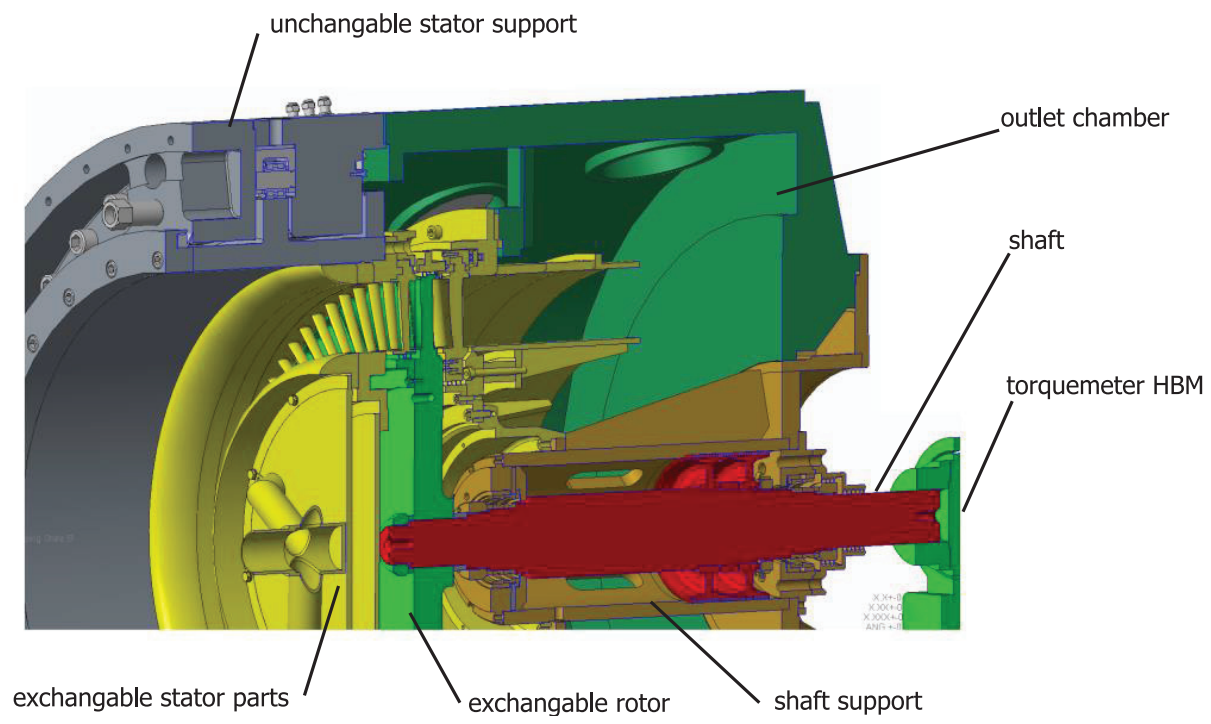

Fig. 1. The original turbine - the one-and-half-stage configuration

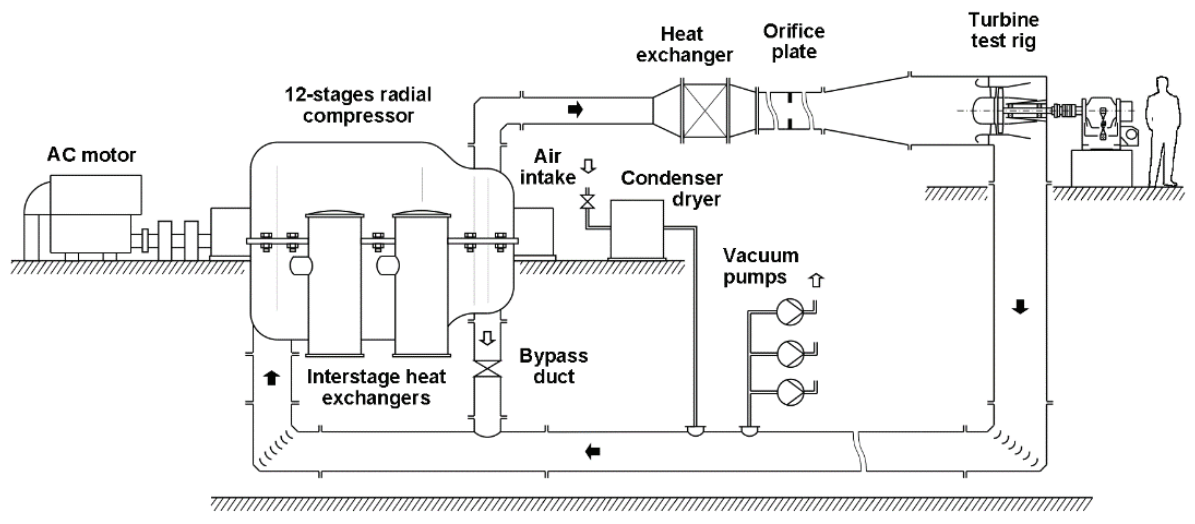

Fig. 2. Closed-loop wind tunnel layout

In addition to enabling the measurement of the characteristics of two axial turbine stages, the goal for the new plant was to eliminate the following disadvantages and limits of the original concept: i) Critical speed, ii) Refinement of mechanical bearing losses, iii) Removal of double skin arrangement. 
The original device had a limitation especially in terms of critical speed, which was caused by insufficient rigidity of the facility structure - frame, outlet chamber, shaft support. Furthermore, it did not allow mechanical measurement of shaft bearing losses. The losses due to bearing friction were estimated by measuring the bearing temperature. Timeconsuming stabilization was one of the disadvantages of such a loss determination.

Another limitation was the double-walled arrangement, which caused problems in setting up the probes and makes optical access difficult when using optical methods. On the other hand, the double-walled arrangement did not require thermal insulation of the stage from the surroundings, and in the case of measurements using thermocouple probes, the error caused by conducting heat from the outside to the sensor itself was reduced.

Two-stage turbine research is typically focused on the interactions of purge flows at the rotor tip (influence of clearance, blade tip shape in the case of shroud-less stages, shroud geometry, shroud output shaping), hub area geometry (shaft seal and its outlet), clocking of both rotors and stators, and the effects of axial clearances of the blade rows. The new facility should therefore allow these activities to be carried out.

To gain an overview and inspiration for the solution of individual key elements of the new equipment as well as for the solution of more detailed structural units, a search of operated two-stage turbines was performed in the literature and on the websites of the most important research institutes focused on the field of turbines.

In general, test equipment for two-stage arrangement is most often focused on the research of the two stages interaction of internal combustion turbines used for aircraft, mostly the transition module between the high-pressure and low-pressure stages. This structural unit is characterized by the fact that the high-pressure and low-pressure turbines have different speeds, which corresponds to the concept of test equipment - double-shaft turbines with each shaft on a separate dynamometer. The following is an overview of some two-stage test turbines.

- $\quad$ DLR - Institute of Propulsion Technology - NG Turb equipment [7]

- Onera, Modane Avriex Center (CMA) - TURMA equipment [8]

- Graz University of Technology - Transonic Test Turbine Facility [9]

- University of Notre Dame - Multistage Turbine Test [10]

- $\quad$ ETH Zurich - LISA equipment [11]

The initial considerations about the basic concept of the facility were mainly based on the analysis of previous activities performed on the original facility within the solved projects. The most common activity of the VZLÚ turbomachine laboratory is the testing of numerous variants of turbine stages for various industrial partners - turbine producers. Therefore, the basic requirement was that the device must be designed to allow a relatively simple exchange of tested stage geometries and to allow the installation of stages of different diameters, limited by a hub diameter of about $220 \mathrm{~mm}$ and a tip diameter of about $600 \mathrm{~mm}$. Another limitation of the measured stages is, of course, the mass flow provided by the compressor.

The ETH Zürich solution can best serve as inspiration for a similar concept - one dynamometer for two stages with the same speed. In addition, very detailed information about the construction is available thanks to the description in the dissertation [11]. The key element of the design is the separate measurement of torques of both stages by means of capacitive measurement of the torsion of two shafts (rotation of the shafts at $70 \%$ of the torque is $4^{\circ}$ ).

The requirement for equipment adaptability (enabling easy exchange of test stage models) is a key requirement distinguishing VZLÚ equipment from most two-stage turbine test equipment operated in the world. However, this requirement significantly complicates the construction and operability of the machine. Due to the requirement of frequent replacement 
of test stages, configuration with mounting the test stages on the overhanging end of the shaft was used. The bearing at this end of the shaft is relatively high loaded, and this conception is more sensitive to vibrations. This led to increased demands on the rigidity of the device. The final design of the facility is shown in Fig. 3. Summary of the new test rig parameters compared with the original facility is written in Tab. 1. A more detailed description follows.

Table 1. Summary of the new test rig parameters

\begin{tabular}{|l|c|c|}
\hline \multicolumn{1}{|c|}{ Parameter } & Original Facility & New Facility \\
\hline Tip Diameter $(\mathrm{m})$ & 0.60 & 0.64 \\
\hline Hub Diameter $(\mathrm{m})$ & 0.20 & 0.16 \\
\hline Number of stages & 1.5 & $2(2.5$ possibly in future $)$ \\
\hline Max rotational speed (RPM) & $\begin{array}{c}10000 \text { (limited due to the } \\
\text { critical speed) }\end{array}$ & 14000 \\
\hline
\end{tabular}

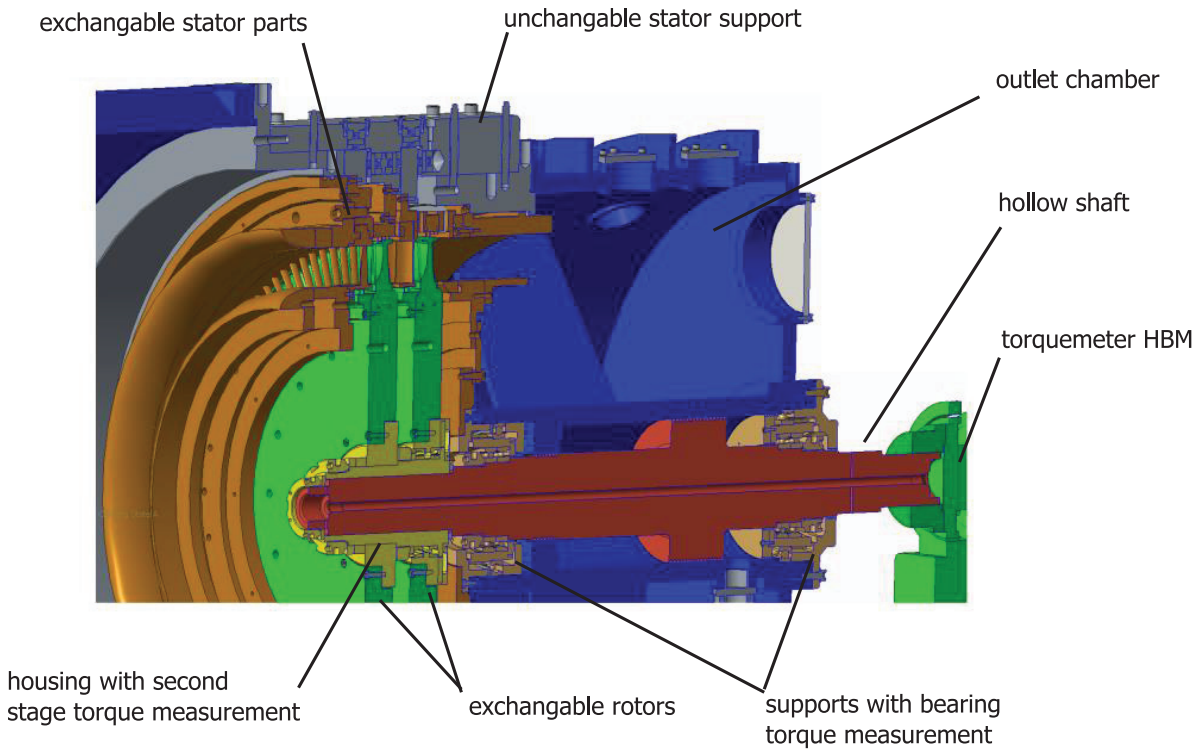

Fig. 3. The new test turbine - two-stage configuration

\section{Design of individual KEY elements}

\subsection{Shaft bearing}

The shaft (Fig. 4) is mounted on angular contact ball bearings, always in tandem on both supports. The doubling of the bearings was performed mainly to increase the rigidity of the supports; at the same time, this solution also brings a longer service life of the bearings due to a lower loading. The design of both bearing supports is unified and consists of the bearings themselves, the bearing housing assembly, and the outer bearing for the rotary bearing housing. This allows the loss torque of the bearing to be measured by a force sensor. Furthermore, the bearing housing is equipped with a thermocouple for monitoring the bearing temperature and with accelerometers for vibration monitoring. The housing design is such that the housing can be rotated about the shaft axis to prevent the outer bearing ring from 
squeezing. It is assumed to be rotated at least four times during the life of the main shaft bearings. The service life of the bearings should be at least $7000 \mathrm{~h}$.

The shaft bearing is designed so that the front support absorbs the axial force in the flow direction (positive). The negative force is eventually absorbed by the rear bearing. The device is not expected to be operated continuously with negative force. The direction and magnitude of the force will be controlled by adjusting the pressure in front of and behind the balance piston. The front support is equipped with force sensors to measure the total axial force. The MST wave spring is used in the assembly for the permanent preload of the bearings.

The shaft assembly is inserted in a housing weldment in which the shaft assembly is supported by five ribs. The housing box also serves as an outlet chamber directing the flow from the turbine to the return path of the closed-loop wind tunnel.

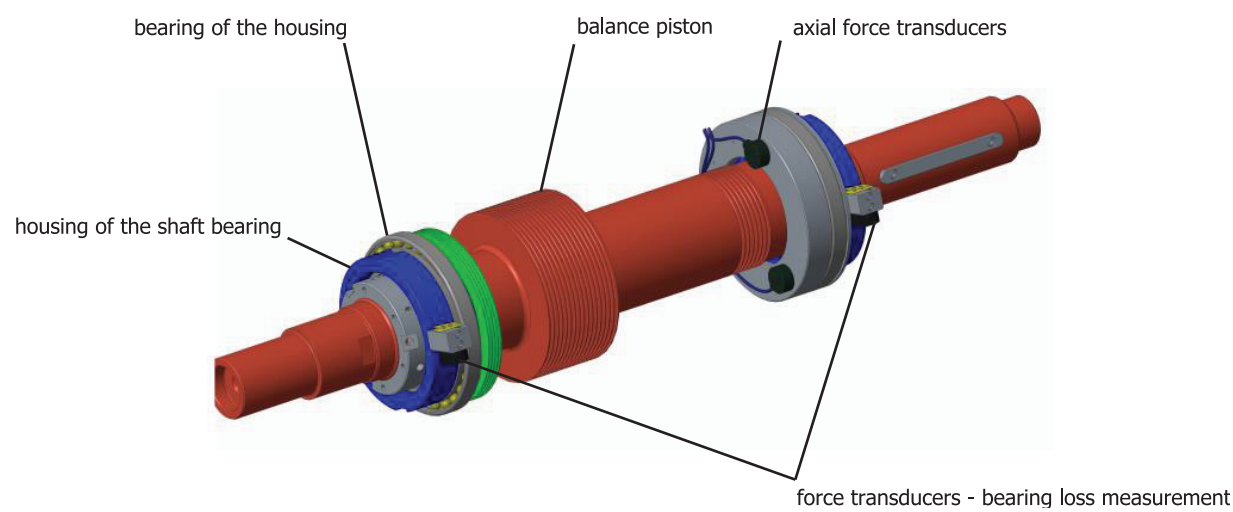

Fig. 4. The shaft assembly

\subsection{Measurement of bearing losses}

The measurement of the overall efficiency of the tested stage is negatively affected by the loss caused by friction in the bearings and the so-called ventilation loss, i.e. the friction of rotating parts by air (especially the disk of the tested stage).

The bearing losses in the original facility were included in the calculation of the stage overall efficiency by an empirical formula based on the measurement of bearing warming. However, the correction determined in this way may not correspond exactly to the actual losses.

For the newly built device, it was decided to use a direct measurement of the bearing response by placing the shaft bearings in housings rotatably mounted relative to the fixed frame. The torque loss is then measured using a force sensor that connects the bearing housing to the frame in a tangential direction - depicted in Fig. 4. The loss moment of each bearing is measured separately, thus the condition of both supports can be easily determined by the force measurement. The support state is monitored also by the thermocouples and accelerometers as was mentioned before.

\subsection{Torque measurement}

For the two-stage turbine, it is necessary to determine the torque of the two stages separately. The torque of both stages together is measured by torque meter HBM which is used to connect the turbine shaft and the dynamometer shaft. A Novel torque meter (Fig. 5) was designed and manufactured to measure the second stage torque. In fact, it determines the differential torque between the first and the second stage. Therefore, the second stage is 
mounted rotatably and the torque is captured by the measurement element which is instrumented by strain gages. A mechanical fuse is implemented in the assembly for safety reasons. The fuse limits the deformation of the measurement element and takes over the transmission of torque in case of a failure of the element. The power supply of the strain gauges and the signal transmission are provided by a one-channel wireless system produced by KMT Telemetry.

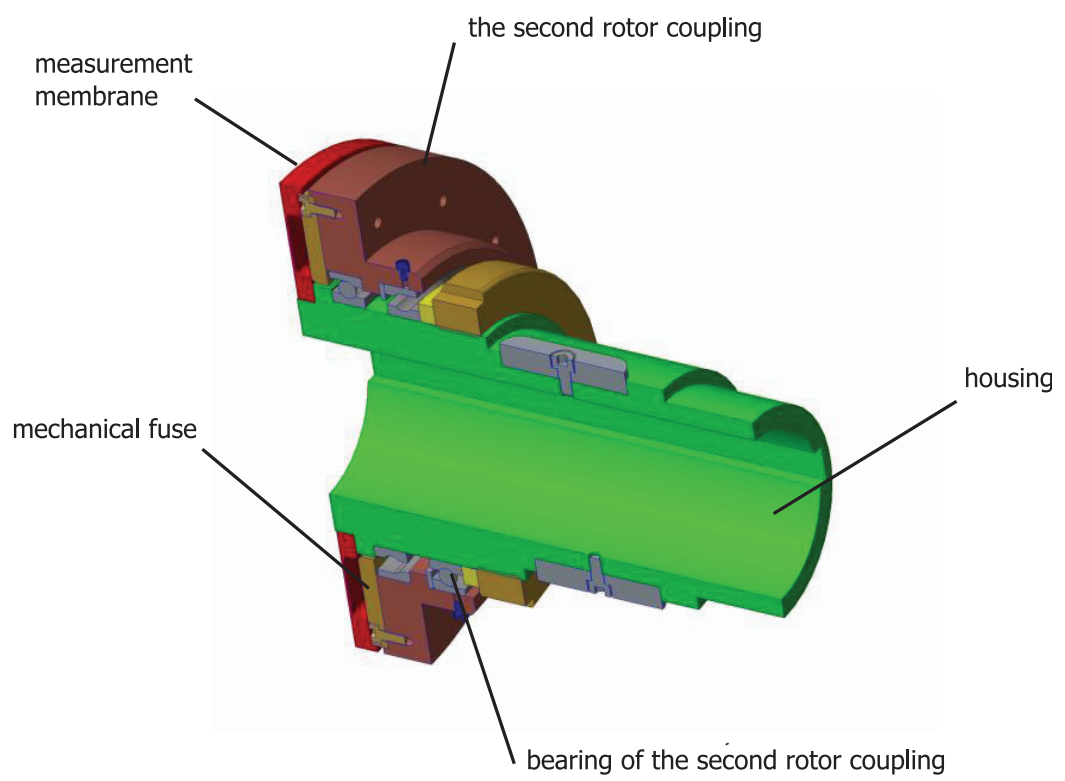

Fig. 5. The second rotor torque meter

\subsection{Concept of rotating stator}

During the implementation of the turbine concept, it was decided to use the concept of linear traverses and a rotating stator. The reasons for the use of this concept were mainly: the reliability of the seal and the possibility to measure the losses of the stage more reliably; and the possibility of individual circumferential adjustment of the stator vanes - the so-called indexing. A significant advantage of this solution is the simplification of the traversing device with the probe, which thus degrades only to a linear displacement with axial rotation - probe routing. This traversing device can then also be easily dismantled from the turbine rig with the probe and used, for example, in the test section for calibrating the probe.

The assembly of the stator holder is shown in Fig. 6, description follows. The rigid structure is consisted of three supports which connects the inlet and outlet consoles. The stators are mounted in holders (each stator has own holder), which are rotatably fitted in the basic structure to allow the flow field to be traversed circumferentially. The supports are fitted with bushings equipped with bearings, which ensure the rotation of the stator with the least possible resistance. This bearing concept is based on the assumption that the force acting on the stators will always act towards the outlet chamber, i.e. in the direction of flow. Therefore, the support bushes are always firmly mounted in this direction (rear), the front bearings are spring-loaded by means of MST wave springs. Similarly, radial bearings are firmly mounted on the lower supports with thrust bolts for precise alignment with the shaft. The upper support has spring-loaded bearings. Fixed support bushes in the axial direction are uniform, pre-sprung cylindrical bushes are used identically for axial and radial supports. 
On the outer shell of the stator housing, there are beds for the connection of traversers with measuring probes enabling their linear radial displacement along the height of the blade. These beds are placed circumferentially by $30^{\circ}$ relative to each other in a total of six positions. The beds allow the traversers to be adjusted in the axial direction to different measuring planes along with the entire two-stage arrangement.

A drive composed of a stepper motor, a gearbox, and a ring gear is used to rotate the stators. The stators can thus be rotated in a circumferential manner of max. $80^{\circ}$ relative to the positions of the measuring probes. The relative angular position of the two stators can be changed manually by a simple mechanism. The clocking can be simply changed also during the facility operation.

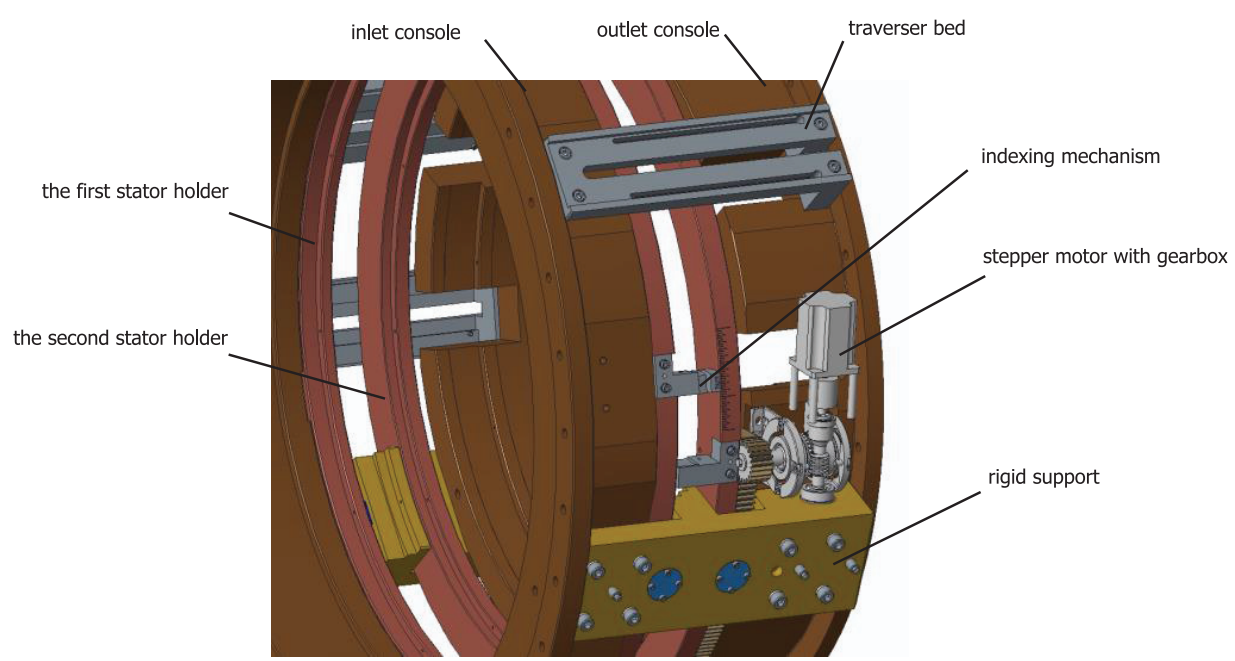

Fig. 6. The stator holder assembly

\section{Trial operation results}

The initial tests on the new test equipment were focused primarily on verifying the vibration behavior and the new approach to measuring the loss of torque, which plays an important role in refining the overall efficiency of the tested turbine stage. The initial testing was performed with a high-speed one-stage axial turbine. Advantageously, the stage was already measured in detail on the original turbine test rig. 


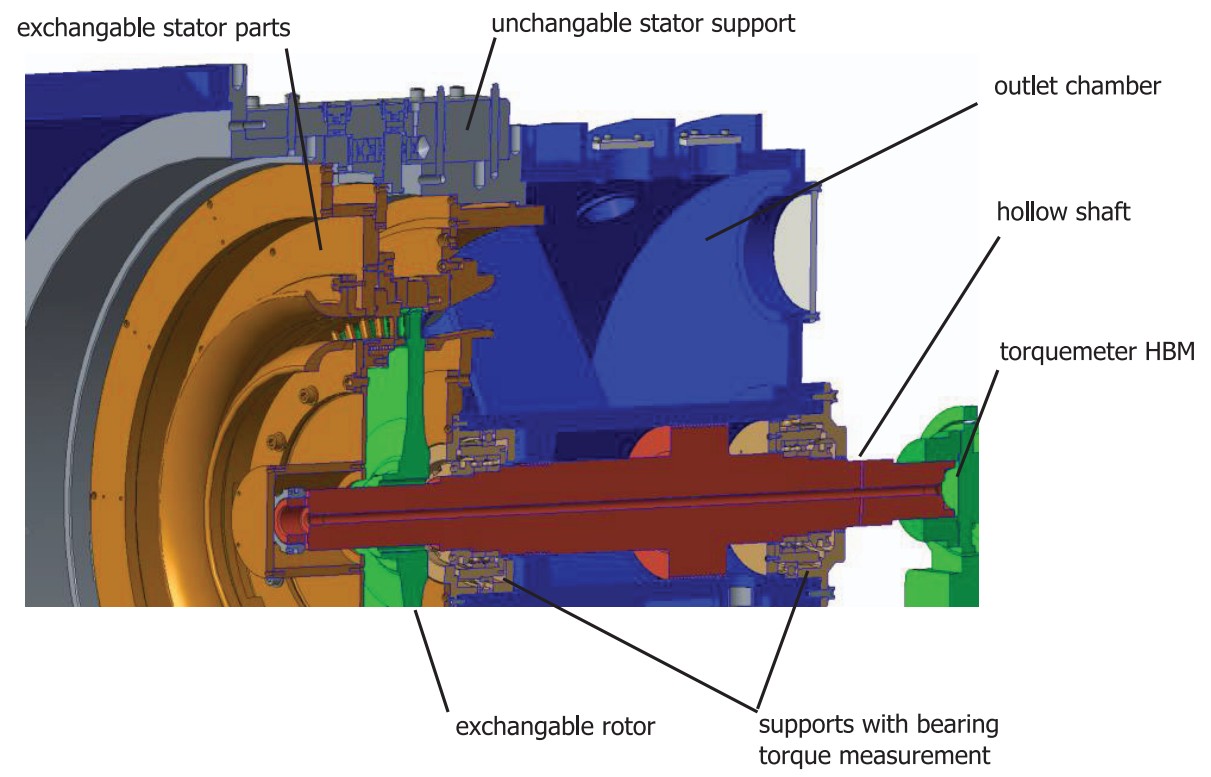

Fig. 7. The new test turbine - one-stage configuration during the first tests

\subsection{Vibrations}

The rotational speed range up to $14000 \mathrm{rpm}$ could be tested with the particular stage. The vibrations of the front bearing and the dynamometer bearing are shown in Fig 8. These results show that the rigidity of the new base frame and the turbine body is sufficient. There are two peaks in the dynamometer vibrations characteristic (4500 and $9000 \mathrm{rpm}$ ). In the case of the novel facility, the peaks are kept sufficiently low thanks to the rigidity. The turbine front bearing characteristic had no significant peaks. Just slightly higher vibrations occurred in the range of the rotational speed from 10000 to $11500 \mathrm{rpm}$. Above $13000 \mathrm{rpm}$, the vibrations grew in all measured places. This is probably caused by the dynamometer behavior.
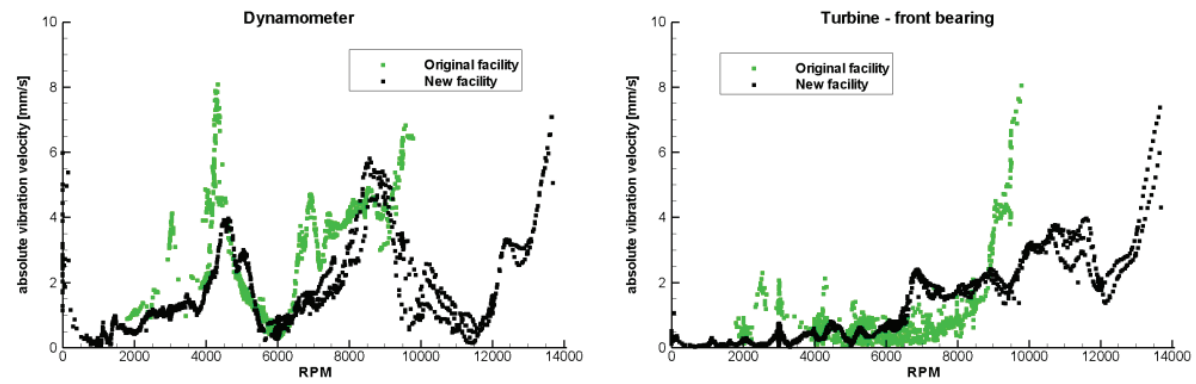

Fig. 8. Vibration characteristics - dynamometer (left hand side) and turbine front bearing (right hand side)

\subsection{Bearing Losses}

Figure 9 shows a bearings loss as a function of the shaft rotational speed. There is the loss computed by an SKF tool [12] for the original test facility compared with the loss estimated 
by the bearing's temperature measurements. The losses computed based on the housing torque measurement in the new facility are also plotted here. One can see the higher loss of bearing in the range up to 6000 RPM. These higher losses were present mainly at the beginning of the operation and in some atypical operational conditions.

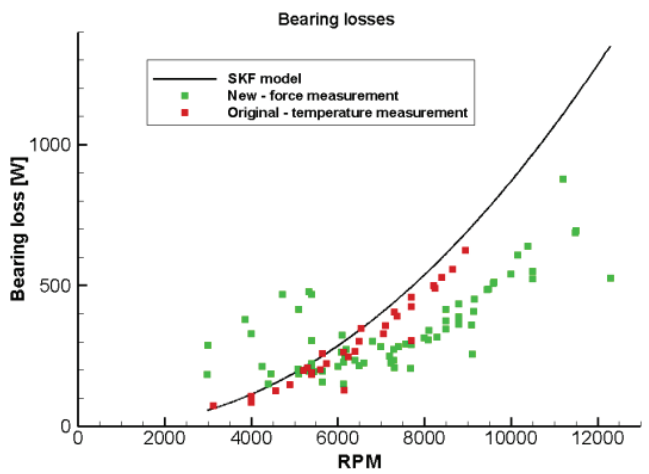

Fig. 9. Bearing losses as a function of the rotational speed

\subsection{The Stage Efficiency}

Overall efficiency measurement is based on the measurement of the torque, mass flow, and pressure ratio. The advantage of the facility reconstruction was, that the key technologies remained the same. The same torque meter was used, and the same configuration of the mass flow measurement was kept. Also, the shaft geometry is very similar, which is important in the ventilation losses determination. The stage tested was exactly the same including the hub and tip channel geometry parts, which was important for the comparison of the results as it influences the pressure ratio determination. Ultimately, the bearings behaviors were the most important difference between the original and novel test facility results.

The comparison of the mass flow characteristic is shown in Fig. 10. It documents that the pressure ratio and the mass flow are measured correctly, and the assumption based on the same configuration is met.

The influence of the determination of the bearing losses on the final efficiency is shown in Fig 11. The SKF model was used for both the original and the new facility, whereas the bearing-torque measurement was used only for the new one.

It shows that the results obtained in the original and in the new facility are well comparable. The effect of the determination of the bearing losses is not so noticeable on the maximum efficiency, but it rather changes the position of the optimum on the individual pressure ratios. The position of the optimum is nearly independent of the pressure ratio in the case of the bearing loss determined with the SKF model. A lower pressure ratio is characterized by a lower optimum speed ratio $\mathrm{u} / \mathrm{c}$ in the case of the bearing loss measured. This result is consistent with the change of the stage reaction, which increases from 0.42 (pressure ratio 1.2) to 0.54 (pressure ratio 1.9), and the measurement of the bearing losses seems more reliable. 


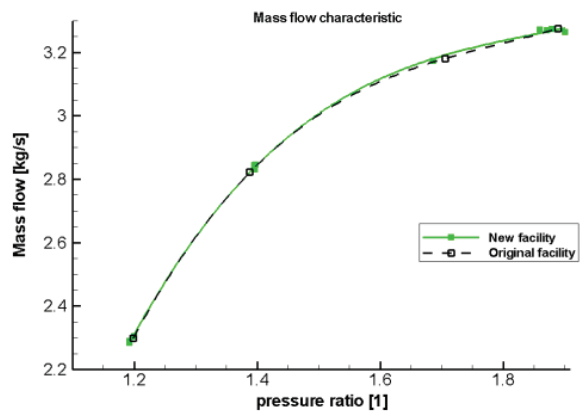

Fig. 10. Mass flow as a function of the pressure ratio - comparison of the original and the new facility
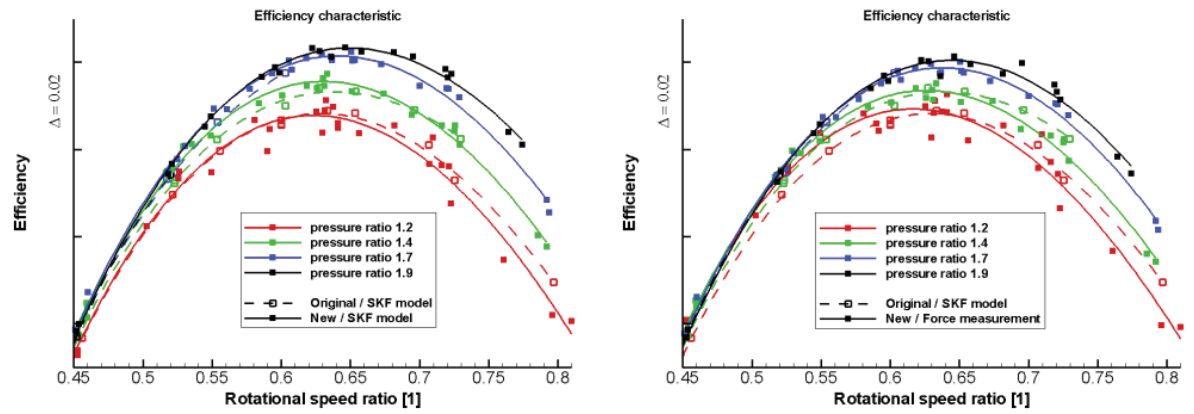

Fig. 11. The stage efficiency characteristics - comparison of the original and the new facility

\section{Conclusion}

This paper summarized the key consideration during the design of the new test rig for aerodynamic research on two-stage axial turbines. The main limitations of the original facility were identified as insufficient rigidity leading to a low critical speed, inability to directly measure bearing losses, and the double-skin arrangement.

The literature review revealed a relative lack of relevant sources since the major bulk of experimental facilities focus on double-shaft aircraft turbines. Therefore, the design of the new facility had to mainly stem from the lessons learned during the long-term operation of the original facility.

The design of the key elements reflecting the specific needs (especially the one of high adaptability) were described. The mounting of the shaft bearings, the measurements of torque and bearing losses, and the concept of the rotating stator were successively discussed. It can be concluded that the proposed design, which meets all the requirements, is manageable using available technical means and resources.

The trial operation of the new facility was successfully performed. The most important quantities were presented and compared with the results coming from the original facility. The initial runs proved that the rigidity of the facility is sufficient, and the rotational speed range is well extended. It is important namely for future experiments focused on turbine stages with high values of the pressure ratio.

This result was achieved with the help of institutional funding of the Czech Ministry of Industry and Trade in the program dedicated to the development of research organizations. 


\section{References}

1. T. Jelínek and M. Němec, "Investigation of Unsteady Flow in Axial Turbine Stage", Experimental Fluid Mechanics 2011, pp.706-716, 2011

2. M. Němec, T. Jelínek and M. Babák, "In-Scale And Up-Scale Full Turbine Stage Measurements As A Support For Small Turbine Units Development", Proceedings of ASME Turbo Expo 2012, Copenhagen, GT2012-69693

3. J. Uher, P. Milcak, R. Skach, D. Fenderl, P. Zitek and M. Klimko, "Experimental and Numerical Evaluation of Losses From Turbine Hub Clearance Flow", In. Proceedings of the ASME Turbo Expo 2019: Turbomachinery Technical Conference and

Exposition. Volume 2B: Turbomachinery. Phoenix, Arizona, USA. June 17-21, 2019. https://doi.org/10.1115/GT2019-90726

4. M. Němec, T. Jelínek, J. Uher and P. Milcak, "Effect of Stage Reaction and Shaft Labyrinth Seal in a Stage of an Axial Steam Turbine." Proceedings of the ASME Turbo Expo 2020: Turbomachinery Technical Conference and Exposition. Volume 9: Oil and Gas Applications; Organic Rankine Cycle Power Systems; Steam Turbine. Virtual, Online. September 21-25, 2020. V009T23A014. ASME. https://doi.org/10.1115/GT2020-14741

5. M. Němec, T. Jelínek and P. Milčák, "An investigation of a flow field in one and half axial turbine stage", AIP Conference Proceedings 1889, 020025 (2017); https://doi.org/10.1063/1.5004359

6. M. Němec, T. Jelínek and P. Milčák, "Clocking of stators in one and half stage of axial steam turbine", EPJ Web of Conferences 180, 02071 (2018); https://doi.org/10.1051/epjconf/201818002071

7. http://www.dlr.de/at/en/desktopdefault.aspx/tabid-7393/12440_read-30128/

8. J-M. Massonnat and T. Coton, "Development in turbine testing at ONERA", 27th AIAA Aerodynamic Measurement Technology and Ground Testing Conference, AIAA 2010-4536, Illinois, 2010

9. J. Hubinka, C. Santner, B. Paradiso, F. Malzacher and E. Göttlich, "Design and Construction of a Two Shaft Test Turbine for Investigation of Mid Turbine Frame Flows", XIX International Symposium on Air Breathing Engines 2009, ISABE-20091293, Canada, 2009

10. http://turbo.nd.edu/facilities/

11. J.P. Schlienger, "Evolution of Unsteady Secondary Flows in a Multistage Shrouded Axial Turbine", Diss. ETH Nr. 15230, Zürich 2003

12. SKF SimPro Quick, https://www.skf.com/group/support/engineering-tools/simproquick 